\title{
The consequences of the Chernobyl accident: "REDAC", the radioecological database of the French - German initiative
}

\author{
G. Deville-Cavelin ${ }^{1}, \mathrm{H}$. Biesold ${ }^{2}$ and V. Chabanyuk ${ }^{3}$ \\ ${ }^{1}$ Institut de Radioprotection et de Sûreté Nucléaire (IRSN), Environment and Emergency \\ Operations Division (DEI) \\ ${ }^{2}$ Gesellschaft für Anlagen- und Reaktorsicherheit (GRS) mbH, Wastes Management Division \\ ${ }^{3}$ Intelligence Systems Geo, Ltd. and Chornobyl Centre for Nuclear Safety, Radioactive \\ Wastes \& Radioecology, Ukraine
}

\begin{abstract}
The French-German Initiative for Chernobyl (FGI), implemented by IRSN and GRS from 1997 until the end of 2003, included the "Project on the Radioecological Consequences of the Accident". The most relevant fields of radioecology and post-accidental aspects have been studied. The main goal was to collect and harmonise in NIS countries, the data and results on these topics. These data have been verified, validated and organized in a common georeferenced database REDAC (RadioEcological Database After Chernobyl). For linking the data, topographic maps and maps of contamination by ${ }^{137} \mathrm{Cs}$ have been used and relevant environmental non-radioactive data have been included. The operational database built will also allow the management of the wastes disposal sites. Countermeasures used after the accident have been described and classified. An evaluation of their effectiveness has been done. The database constitutes a tool for the development and validation of operational, assessment and explicative models. This allows the quantification and assessment of radionuclide transfer in the ecosystems. The main parameters influencing the transfers can be identified. REDAC should be completed by further investigations, for example on transuranic elements, and extended to larger geographical zones and combined with others provided by different organisations.
\end{abstract}

\section{GOALS}

In the frame of Project 2 "Radioecology", REDAC was developed in an additional sub-project "Soft integration of databases" in the last of four years of Project implementation. The goals of REDAC creation can be classified according to the usage, subject and system worlds of created information system. The usage world is the most principal. Subject and system worlds are depending of the usage world. FGI Project 2 usage world is defined by the needs of four groups of potential users: public, scientific, decision-making and support.

REDAC goals are:

- To create integrated database of Project "Radioecology" sub-projects 0-5 databases, which is logically unique for the four groups of potential users.

- To integrate REDAC into the FGI partners business processes. More exactly, REDAC should work in Chornobyl Centre for Nuclear Safety, Radioactive Wastes \& Radioecology (ChC) as the element of IRSN-GRS-ChC scientific network. 
- To solve some Project 2 subject world integration problems. They are: 1) search and unique definition of the same thematic entities in the Project 2 sub-projects databases, 2) creation of the integrated view of radioecological consequences of the Chernobyl accident.

- To solve system world integration problems in coordination with usage and subject worlds. In addition to the solution of standard integration problems it should be solved geocoding problem - all thematic data should be geocoded with the usage of unique topographic map.

\section{INVESTIGATION RESULTS}

The area of investigation is Project "Radioecology" Sub-Projects 0-5 databases also as themes, which they are representing, namely:

SP 0: Ecological Portrait,

SP 1: Contamination of the Environment,

SP 2: Waste Dumps and Waste Strategies Management,

SP 3a: Soil-Plant Transfers,

SP 3b: Plant-Animal Transfers,

SP 3c: Runoff in an Agricultural or Natural Environment,

SP 3d: Transfer in Aquatic Environment,

SP 4: Urban Environment and Countermeasures,

SP 5: Countermeasures on Natural and Agricultural Areas.

The main question of investigation was "How to reach representation of the nine Sub-Projects databases for application or user as a logically unique database?"

\subsection{Specific methodology}

To fulfill the defined goals the specific methodology was created. This methodology is named Project Solutions Framework (ProSF). ProSF is an information system of practically verified patterns intended for simplification of the main project activities.

ProSF is based on the following principles:

- The resulting system should be information system in a wide sense (ISW). ISW is totality of all formal and informal data representation and processing activity within an organization (for example, Chornobyl Centre), including the associated communication, both internally and with the outside world.

- ISW should be developed as the project portal.

- The project portal should be soft integrated information system:

1) common use data should be found and embedded as a global database layer into the Project 2 Sub-Projects databases,

2) HTML should be used as a main tool for linking of all information and software objects in resulting ISW.

- The project portal should be geoinformation system - all thematic spatial data should be geocoded by the means of a uniform topographical map. Geoinformation tools should be used for a manipulation by these data.

\subsection{Structure of the database}

REDAC3W is a set of five packages of the elements: Publications, Products, Processes, Services, and Basics. Certain relations are created between these packages. Contents and relations of packages are determined by ProSF concept. 
Products package is intended for users who are interested to have direct access to the "classical" information products prepared according to the templates Contains the basic electronic results of each Sub-Project.

Publications package is intended for storage of open publications of Sub-Projects results.

Processes (Sub-Projects) package is intended for managers of the Project 2, and also managers who will solve similar tasks in similar projects. Contains two sections: Working Plans\&Reports, Management Process.

Services package contains service information and software objects. Service information objects are: information about Project 2; on-line help; connection with electronic storage of original production of the Project 2; file of the description of all printed production, received in the Chernobyl Centre and stored in the paper storage; information about Project 2 participants; service design elements.

Basics package is intended for storage of the information objects being determining as for system development processes or project implementation processes, and for the organization of all information and software objects of Sub-Projects in "weak" or "soft" integrated system.

\subsection{Main scientific and technical results}

The main scientific and technical result of the Sub-Project SP6 of the Radioecology Project is soft integrated geoinformation system REDAC3W, including all final results and the important intermediate results of the Project 2 on Radioecology.

\subsubsection{Scientific content of REDAC}

All specific results of the sub-projects are gathered in the database according to methods and the structure described in paragraph 2.3.2 and followings.

For the different sub-projects, the nature and number of data is briefly given in the below Table .

Table 1. Content of REDAC for the main categories of data.

\begin{tabular}{|c|c|c|}
\hline Sub-project & Nature of data & Number \\
\hline 0 : Ecological portrait & $\begin{array}{l}\text { Administrative data in the three NIS countries: 20oblasts, } 432 \text { raions) } \\
\text { settlements } \\
\text { Geocoded maps (vegetation, roads, railway, hydrography, relief, ...) }\end{array}$ & $\begin{array}{r}30909 \\
12\end{array}$ \\
\hline 1: Contamination & $\begin{array}{l}\text { Average soil contamination (official) } \\
\text { Direct measurement of contamination (original) } \\
\text { Meteorological data }\end{array}$ & $\begin{array}{r}1011 \\
\mathbf{3 2 0 9 7} \\
5145 \\
\end{array}$ \\
\hline 2: Wastes & Geographical location of wastes disposals and related content ${ }^{1}$ & 550 \\
\hline 3a: Soil-plant transfers & $\begin{array}{l}\text { Contamination of soils, including forests } \\
\text { Contamination of plants and transfer factors }\end{array}$ & $\begin{array}{l}5970 \\
\mathbf{6 5 7 4} \\
\end{array}$ \\
\hline 3b: Transfers to animals & $\begin{array}{l}\text { Contamination of fodder and forage, including for game } \\
\text { Contamination: meat (+game) and milk and transfer factors }\end{array}$ & $\begin{array}{l}9770 \\
7154\end{array}$ \\
\hline 3c: Transfers by runoff & $\begin{array}{l}\text { Meteorological data } \\
\text { Soil and experimental plots contamination } \\
\text { River contamination and runoff coefficients (\&Test of models) }\end{array}$ & $\begin{array}{r}34635 \\
3826 / \\
\mathbf{7 1 3 3}\end{array}$ \\
\hline 3d: Transfers in aquatic ecosystems & $\begin{array}{l}\text { Contamination of the aquatic environment } \\
\text { Contamination in fishes (\&Test of transfer models) }\end{array}$ & $\begin{array}{r}2500 \\
459\end{array}$ \\
\hline 4: Urban transfers, countermeasures & $\begin{array}{l}\text { Dose rate in streets and houses } \\
\text { Efficiency of decontamination methods }\end{array}$ & $\begin{array}{r}7027 \\
\mathbf{3 0} \\
\end{array}$ \\
\hline 5: Countermeasures & $\begin{array}{c}\text { Countermeasures and efficiency: } \\
\text { Plant productions } \\
\text { Stock-breeding } \\
\text { Meadows ecosystems } \\
\text { Forest ecosystems } \\
\text { Technological processing }\end{array}$ & $\begin{array}{r}5261 \\
1916 \\
681 \\
1783 \\
98 \\
783 \\
\end{array}$ \\
\hline
\end{tabular}

\footnotetext{
${ }^{1}$ After completion through a completary program developed by GRS and IEG Kiev.
} 


\subsubsection{Soft integration}

Soft integration is carried out both software, and information methods and tools. All elements of production of the Project 2 are organized in special storage which refers to as Element / Document library. Work with this storage is carried out by TriNet software. In TriNet there are the special mini-applications realizing business functions and processes. They refer to as Portlets. Portlets are consisting of Webs parts. Portlets and Webs parts form Digital Dashboards (DDB). Digital Dashboards form DDB site. DDB sites are adjusted for needs of the concrete user depending on his rights of access.

Each REDAC user can have coordinator, author or reader rights. Coordinators have access to all REDAC functions. Authors are authorized to change the certain documents. Readers are authorized to read the certain documents.

REDAC is the portal or Internet/Extranet/intranet application. It means that REDAC users can work with the system through local network, corporate network or through the Internet.

A - Document library Portlet: The Document Library portlet includes Webs parts (Figure ):

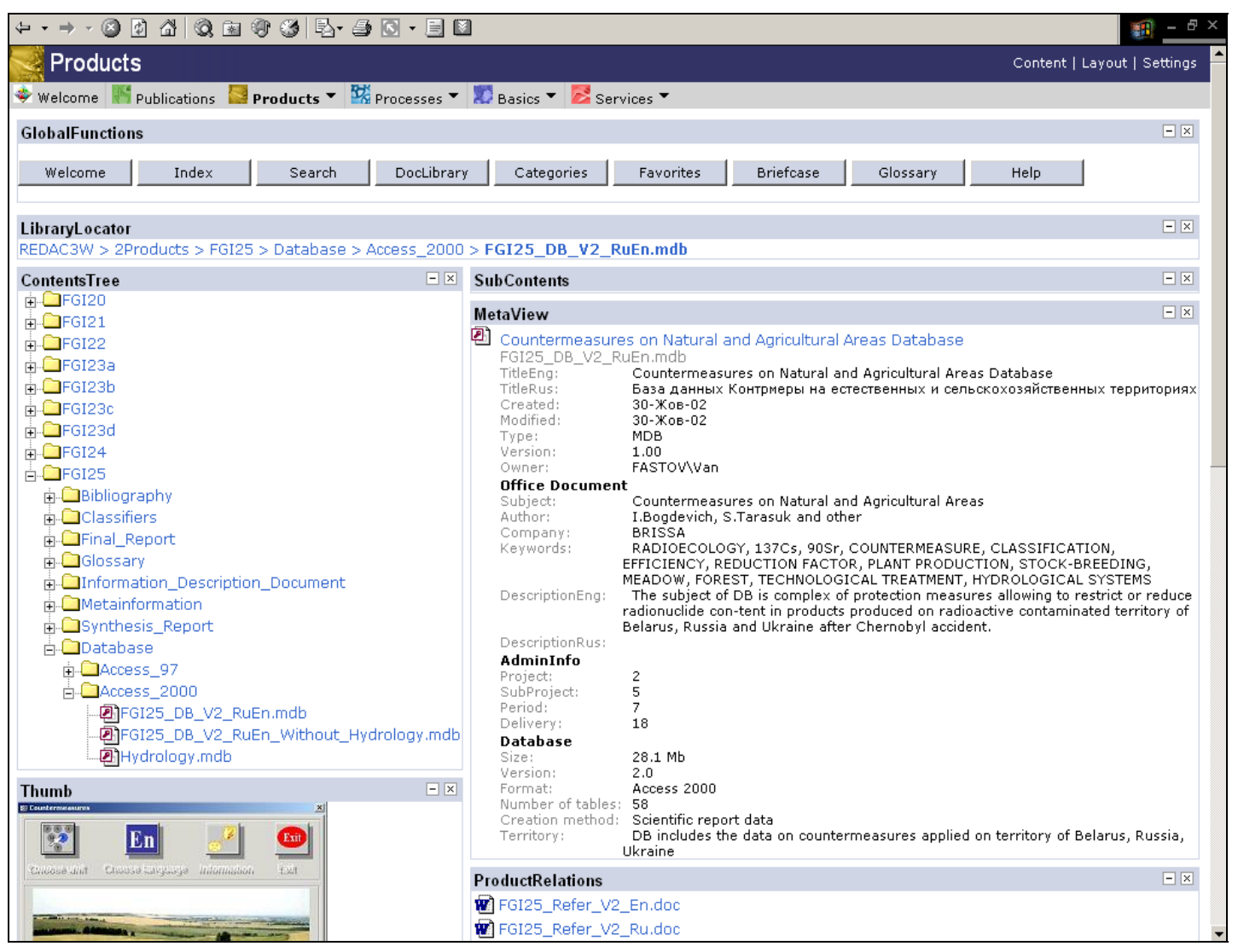

Figure 1. Document library Portlet interface - example of the Sub-Project 5 "Countermeasures" production.

GlobalFunctions - connection with other Portlets simplifying work with documents.

LibraryLocator - shows the location in the library.

ContentsTree and SubContents help to carry out navigation within the library. It shows the structure, content and names of library folders. Thumb shows the thumbnail image which most clearly characterizes this element / document. 
MetaView shows metadata - the data about elements / documents in the library.

ProductRelations- shows the relations established between a database file and documents describing it: It is important to note, that in the special manner structured documentation is an integral part of a product of each Sub-Project of the Project 2.

DocView (not shown on Figure ) - displays the file / document loaded from the Web-server.

B - Portlets, supplementing the Document library

GlobalFunctions Web part is connected to other Portlets:

Index Portlet - search of documents by the Index, i.e. beforehand-prepared list of key words.

Search Portlet - search the documents by the auxiliary words, properties, and file extensions, categories.

DocLibrary Portlet (Document Library) - is described above. In this case provides an exit in a root of document storage and access to the described above navigation and visualization functions.

Categories Portlet - works with document categories. Categories mechanism allows to create virtual groups of documents in addition to the groups which are created physically at creation of system folders on a hard disk. Files thus are stored only once in some folder.

Favorites Portlet - the user can generate a set of files by this or that principle (for example, most often used files).

Briefcase Portlet - the necessary files can be postponed in the Briefcase so that after end of a session to load them to the user computer.

Glossary Portlet - supports work with the Global glossary of the Project 2. The Global glossary is constructed based on glossaries of Sub-Projects. Each term in the Global glossary has the reference to the source glossary.

C - Cartographical integration: The map of Project 2 territory created in Sub-Project "Ecological Portrait" (FGI20, on the data from a DB "Topography") by means of DB GeoObjects and AdmTer has been integrated with thematic databases of Sub-Projects. Results of integration have been loaded in library of documents as documents of a special kind: MapLayers and MapSpaces. MapLayers and MapSpaces can be viewed by means of the ISGeo Internet Map Server which is delivered in together with TriNet software. The big set of the cartographical functions intended for the visual analysis of the data is given the user: scaling, navigation, extracting of the information on objects, management of displayed layers.

It is important to note, that thematic databases are external in relation to MapLayers and MapSpaces. It means, that they can be arranged without change of a cartographical part architecture of the system.

It is also important to note that the received cartographical results became possible due to application of the method of geointegration. The method of geointegration was developed in Sub-Project "Ecological Portrait" (FGI20) as a core of weak integration. This method is using for geocoding special attribute DB of GeoObjects, instead of imperfect and hard-accessible cartographical DB.

\section{CONCLUSIONS}

REDAC3W is powerful and rather useful tool for work both with radioecological databases, and with other results received in the Project 2 "Radioecology".

All elements of final and important intermediate production of the Project "Radioecology" are processed and placed in special storage - Element / Document library. Placed in Document library elements are soft integrated. For integration the next tools and means are used:

Access to all elements is carried out uniformly by the browser and with use of modern Digital Dashboard technologies.

The main expected results of the Project 2 Sub-Projects - databases - are constructed by aggregation of files of databases and the documentation accompanying them. The result of aggregation refers to as a product. Relations are established between the product elements.

All elements of production are supplied with the structured metainformation. For structuring the method of document Profiles is used. 
There are two mechanisms of search of the necessary elements - index and auxiliary. Auxiliary search is carried out by the definition of any words, properties, expansions of files, categories.

Besides physical structuring of elements - their writing in certain library folders - structuring is used by categories mechanism.

Based on glossaries of Sub-Projects the Global glossary of the Project is constructed. Each term in the Global glossary has the reference to the source glossary.

All spatial data are geocoded by means of databases of Sub-Project FGI20: Topography, GeoObjects, AdmTer. Thematic cartographical working spaces (MapSpaces) are constructed for cartographical visualization of results.

One of the greatest interests from the scientific and technical point of view is that all the process, tool and methodology for building REDAC are suitable for any similar project. The structure of the database make very easily usable for scientists and decision makers. The basic database should be also enriched by new results and data.

\subsection{Outlook for REDAC}

In the near future, it would be reasonable to develop some additional and principal REDACW functionality and scientific support and maintenance of REDA3W operation in Chernobyl Centre (Kiev) and in International Chernobyl Centre (Slavutich).

It appears that results of operation REDAC $3 \mathrm{~W}$ has only strengthen confidence that so-called "strong" integration is necessary for the radioecological data. "Strong" integration can be carried out on two basic directions:

- Thematic integration.

- Information integration.

Within the framework of thematic integration, it is necessary to offer decisions on integration of databases of all Sub-Projects. Combinations of thematic integration and links are possible. Information integration should consist in the decision of "classical" information tasks of construction of the integrated database, and also in information support of all listed above combinations of thematic integration.

\section{References}

[1] Deville-Cavelin G., Biesold H., Chabanyuk V., Brun-Yaba Ch., Rutschkowsky N. \& Friederichs H.G. - Synthesis Report of the Radioecology Project of the French-German Initiative for Chernobyl - FGI Report 04-01, 2004 (IRSN-GRS publishers, 2004) [to be going to press]. 